\title{
Teachers' explanations of student difficulties with gravitational potential energy
}

\author{
Michael C. Wittmann, ${ }^{1,2}$ Carolina Alvarado, ${ }^{2}$ and Laura Millay ${ }^{2}$ \\ ${ }^{1}$ University of Maine, Department of Physics and Astronomy \\ 5709 Bennett Hall, Orono, ME, 04469-5709 \\ ${ }^{2}$ University of Maine, Center for Research in STEM Education \\ 5727 Estabrooke Hall, Orono, ME, 04469-5727
}

In a teacher professional development meeting, teachers were asked a question about potential energy and then to discuss why students might give a particular response to it. Working together in a large group, they came up with responses and explanations that touched on multiple ways of thinking about en-ergy and how these might affect student responses. We observed that teachers were aware of common met-aphors for thinking about energy (like energy-as-a-substance) and that they gave multiple explanations for how students might have difficulties in applying these metaphors (e.g., energy is "used up" because of trav-el time, travel distance, or the effort exerted during travel). Additional explanations showed that teachers recognized how students might bring these ideas to the classroom. We discuss the need for teachers to respond to multiple grain sizes of student thinking, including the metaphors they use and the different facets of each. Assessments that help with this will be of greater value to teachers than the assessment we present.

\section{INTRODUCTION}

Given pressures put on teachers to document their own effectiveness [1] and assess students more regularly as part of the Next Generation Science Standards [2], members of the Maine Physical Sciences Partnership (MainePSP, NSF 0962805) have developed a model of professional development in which teachers explore their content understanding and teaching strategies in the context of discussing student work. Using either the questions themselves or student responses to these questions as starting points, we have engaged teachers in discussions where incorrect ideas are named, reasons for their use are discussed, and pedagogical strategies to address student weaknesses are presented and analyzed. Throughout, we are influenced by Deborah Ball and collaborators' discussion of Mathematical Knowledge for Teaching [3] and the professional development activities of Cognitively Guided Instruction [4]. We hope for teachers to gain the tools to be more responsive to their students' ideas as they focus on the disciplinary substance of student ideas [5].

We argue that teacher responsiveness requires assessments that provide useful insights into student reasoning. When a question contains useful metaphors (in our case, the metaphor of energy as a substance) that can be applied in multiple ways (in our case, different and problematic facets of the energy-as-a-substance metaphor), teachers are left with a teaching dilemma. In this paper, we investigate and describe this dilemma in teaching energy.

\section{SETTING FOR RESEARCH}

The MainePSP has brought together the University of Maine, nearly thirty school districts with nearly 50 middle and high schools, as well as many non-profit organizations (the SERC Institute, Maine Math and Science Alliance, and
Institute for Broadening Participation) and the State of Maine Department of Education to reform and vertically align science education in rural school districts. As part of these efforts, physical science classrooms adopted a common curriculum with a unit specifically on energy, including potential and kinetic energy.

To assess student growth in understanding over time (in the school year) and across the project (in successive school years), educators, researchers, teachers, and staff in the MainePSP developed surveys on energy, force and motion, and earth science topics, with questions taken from a variety of sources or developed in-house. This paper looks at the topic of Gravitational Potential Energy (GPE) and topics related to path dependence, related to common errors about conservative forces (discussed below).

\section{DATA COLLECTION}

One of the questions featured in the survey concerned three hikers of the same weight and height walking three different paths from the same starting point to the top of a mountain [6]. The path taken by Hiker 1 was the shortest, going up the steepest path, while Hikers 2 and 3 wandered a bit up and down hills and through valleys before also reaching the top (see Figure 1). Students were asked, "which hiker will have the greatest amount of gravitational potential energy?" - Hiker 1, Hiker 2, Hiker 3, or "The gravitational potential energy is the same for all of the hikers" (the correct response). A correct answer assumed that the energy of the hiker was a stand-in for the potential energy in the hiker-Earth system. Among the teachers, there was no discussion of the nuance of how potential energy can exist without considering the system of Earth and hiker.

As part of a professional development (PD) activity about a month into the school year, this question was used as a starting point to discuss multiple models and metaphors 
of energy. Previous discussions within the MainePSP had established this method of interaction as being a productive one that teachers enjoyed. Other events from a different activity that evening have been described previously [7].

The specific question asked (by author MCW) was, "Why might they say hiker 1 steep, hiker 2 meander, hiker 3 really long winding path. What might be their reasoning for choosing one of those answers?" The reason for the suggestive language (steep, meander, long and winding) is not included in the video but arose from phrases teachers had used earlier in the evening.

Data were gathered by audio- and videotaping 25 teachers as they discussed the question and gave possible reasons for giving a particular answer. Because of the crosstalk and inability to distinguish between voices (and because the nature of our analysis does not require knowing individual teacher names), we were only able to use the elements of discussion that involved the large group setting.

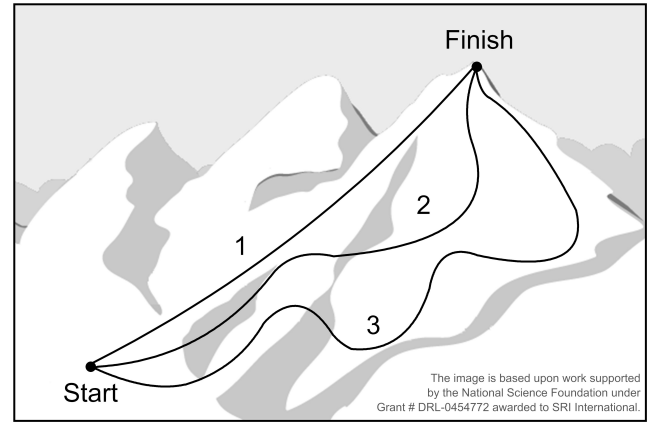

FIG 1. Graphic provided for the Hiker Question [6].

\section{TEACHERS PROVIDE MULTIPLE EXPLANATIONS FOR INCORRECT ANSWERS}

Teachers provided 6 distinct explanations for why Hiker 1 might be chosen as having the highest GPE, five of which had physical reasoning. One, that a "lazy student" unwilling to read very far would pick Hiker 1 because it was listed first, will not be discussed further. Similarly, we will not discuss "Hiker 1 would get there first," because it does not concern specific thinking about energy.

In this section, we present the teacher statement followed by our interpretation of it. In the following section, we discuss how these responses affect our (and teacher) thinking about student reasoning in the classroom.

\section{A. Students believe energy is created}

In explaining why a student would choose Hiker 1, one teacher stated, "Because [Hiker 1] worked the hardest to get up the mountain." We analyze this and subsequent quotes in terms of the reasoning a student might use when giving such an answer, focusing on the metaphors of energy and the actions of the hiker.

For this teacher, a student might think in terms of the amount of effort exerted by Hiker 1. In a commonly used definition, energy is the ability to do work. A student could easily reverse the logic of that sentence: energy is created by doing work. Because this hiker is working the hardest to get up the mountain, more energy is created. As a result, this student would have the greatest GPE at the top.

The idea that more energy is created by working harder is contrary to the models of energy being used up, described below. In Lancor [8,9] and Brewe's [10] research, we do not see use of this metaphor in student thinking. We also do not believe that this answer is related to the stimulus ontology described by Scherr et al. [11]. A more exhaustive exploration of what the teacher was thinking, or a detailed student response along these lines, would allow for further investigation of the thinking involved in giving this response to justify Hiker 1 as having the highest GPE.

\section{B. Students believe energy is a trait of the hiker}

To explain why a student might say Hiker 1 had the greatest GPE at the top, a different teacher stated, "Because they chose the harder path, they're someone who is in better shape." Again, we look at metaphors, actions, and the assumptions that are part of the proposed student response.

For this teacher, a possible explanation comes from thinking about energy as a trait of the hiker. The person who could take the harder path would have to be in better shape, so they must intrinsically have more energy than another hiker, who takes the easier path (like Hiker 3).

This answer is perhaps related to the "energy is a life force" explanation described in [8]. Notably, it is unclear if this explanation shows energy changing as the hiker moves up the mountain. It suggests that energy is an intrinsic property of the hiker, independent of the situation the hiker is in. Again, this is unlike the stimulus ontology described by Scherr et al. [11], because the energy is not a stimulus to action, but is an inherent trait of the hiker instead.

\section{Students believe energy is used up}

Given the prevalence of the "Used up" reasoning in the literature (we cite [8-11], but the broader literature on student ideas contains many examples of this explanation), we expected to find two different ways in which Hiker 1 might use up energy on the way to the top. Teachers arrived at a third that included a place-based explanation, as well. In each of the three cases, the proposed model clearly makes use of the energy-as-a-substance metaphor [8-11]. There is a quantity of energy that the hiker has and some is left over at the end. The issue lies in how the energy was used up. In section IV.D, we discuss an example in which energy could be replenished, as well.

\section{Energy is used up over time}

A teacher stated, "Maybe [Hiker 1] got there first, most direct path, they got there first, so they had more energy left over." 
For this teacher, the model a student might use includes the idea that there is a finite amount of energy in a person at the start of a trip, and that energy gets used up while walking. Because the path is the most direct of paths and Hiker 1 gets to the top first (while perhaps assuming that the 3 hikers move at the same speed), less energy would get used up along the way. The hiker would be left with more than the others.

\section{Energy is used up over a distance}

One teacher said, "they would just see shorter path, not steeper path, so they would say 'oh, it took less energy to get there'." As before, this teacher is focusing on energy loss while moving along the path.

Like in the previous explanation, there seems to be an assumption of a fixed amount of energy at the start of the trip. When going on the shorter path (regardless of its steepness), the hiker would use up less energy to get there. We note that we are interpreting "took less" to mean "used up less," as opposed to assuming that "took" means "gathered from someplace else." Because of the short path (in terms of distance, not in terms of time traveled), the hiker would be left with more than the others.

\section{Energy is used up on steep paths}

Where the previous teacher had explicitly discounted steepness, another teacher said, "[the] guy used his all up, going up that steep path." We note that this is an explanation of why someone would not choose Hiker 1 as an answer. We focus on the nature of the explanation to highlight the ways teachers think about this situation.

For this teacher, it seems that a student might think that it takes more energy to go up a steep path. As opposed to saying that this person is in better shape (and has more energy), as stated in IV.B, or that the steepness would lead to harder work (and higher energy at the end, as in IV.A), going up the steep path would "use up" all the energy. For this explanation, Hiker 3 would have the greatest energy at the top, since that path is, on average, the least steep.

\section{Students may show complex combinations of ideas}

A nuance arose as teachers discussed hiking on a steep path, referring to a local mountain (Katahdin) with one very steep, nearly cliff-like path (Cathedral) and another more even path (past Stream Falls) to the peak. As a teacher stated, "They could also be thinking of their hiking experience ... like, thinking of Katahdin, ... Cathedral is straight up [group laughter], [but] if I go Stream Falls, I've got the plateau to rest,... just thinking about places the students maybe have hiked." We note the laughter of the teachers in the room, indicating they recognize the hike and the path. We also note that the reason someone going past Stream Falls (akin to Hiker 2 or 3, compared to Hiker 1) would have more energy is because they had a chance to rest. This sug- gests some amount of energy recovery due to sitting, not just energy loss due to hiking.

To interpret this result, we again see evidence of the energy-as-a-substance metaphor [8-11], where that substance can be replenished by resting (on a plateau). Possibly, this rebuilding of energy is a mixture of the "used up" explanation (IV.C) attached to the "trait of a hiker" explanation (IV.B) in that people get tired, but return to their baseline energy, given a chance.

\section{DISCUSSION}

We discuss two issues related to these data. The first is about how we model student reasoning. The second is about how a teacher might respond to assessment data in their teaching. We argue that useful ideas can be used in problematic ways, making the task of teaching difficult. We further argue that assessments which do not help clarify student thinking make this task harder.

\section{Facets and metaphors in the classroom}

In the research literature (using [8-11] as examples), we find discussion of various metaphors, primarily the energyas-a-substance metaphor but also the stimulus ontology, the life-force metaphor, and more. In the examples of possible student responses, teachers provided a nuanced view of how these metaphors apply to classroom practice. To interpret these views, we turn to Minstrell's facets of knowledge [12,13].

We have argued for a substance metaphor when interpreting the statement that a hiker has a certain amount of energy that is used up while hiking. We have also observed teachers presenting three different interpretations of this metaphor, one related to time traveled, one related to distance traveled (explicitly not attending to steepness), and one related to the steepness (and perhaps, therefore, the effort) of the travel. These are three different interpretations of the same idea. In Minstrell's language, they are different facets of the same metaphor.

From a teacher's perspective as they interact with and listen to students, one might need to hear both the metaphor (of energy-as-a-substance) and the facets (thinking of a particular way in which substances get used up). The substance metaphor is of value to novices and experts alike [14], so a teacher might seek to sustain students' use of the idea while addressing that some facets of it may be problematic. The teacher needs to determine whether the used up facet is a problem in and of itself, or if a version of the idea might be useful for instruction. A teacher might consider whether GPE is used up as a falling ball gains kinetic energy, e.g., if there are ways to modify the used up idea to look at forms of energy rather than total energy, for example. Similarly, the different facets (based on time, distance, and effort) might present value in some situations and be problematic in others. 
Regardless of how the teacher responds to the students, it is clear that researchers need a nuanced view of teachers, students, and knowledge when studying the teaching and learning of energy. Some facets of ideas have value, while others are a problem in some particular setting. Some ideas might seem problematic but have value in later discussions [15], and the teacher is faced with the difficult task of recognizing the many different ways a single idea can play a role in the classroom.

\section{Assessing how energy is used up}

With so many compelling arguments for Hiker 1, students might easily be distracted from saying that all three hikers have the same GPE at the top. For those who answered correctly, we can conclude that the issue of path dependence, which so clearly distinguishes Hikers 1, 2, and 3 , did not distract them. We might also assume that they recognized that GPE depends only on one's location (on the hill). We should not assume that they have thought about the equivalence of these explanations, though. In sum, answering the hiker question correctly gives relatively strong evidence that students are thinking appropriately about gravitational potential energy.

Problems arise when a teacher tries to find value in or guidance from the incorrect responses a student might give. In our data, discussed with teachers later that evening, roughly $40 \%$ of their students had answered "Hiker 1 " at the beginning of the school year. What did this response mean? It might mean any of the explanations given above.

A responsive teacher giving the hiker question as a pretest would like to be able to use these data to guide decisions about instruction. When $40 \%$ of the students answer Hiker 1, there is no guidance for how to address their needs. Are they thinking hikers use up energy, and in which of the three ways? Are they thinking that Hiker 1

[1] S. Mead and Bellweather Education Partners, Recent State Action on Teacher Effectiveness: What's in State Laws and Regulations? (2012). Available online at http://bellwethereducation.org/publication/recent-stateaction-teacher-effectiveness. Last retrieved June 21, 2016.

[2] Achieve, Inc. (2013).

[3] D. L. Ball, M. H. Thames, and G. Phelps, J. Teach. Educ. 59, 389 (2008).

[4] T. P. Carpenter, E. Fennema, P. L. Peterson, and D. A. Carey, J. Res. Math. Educ. 19, 385 (1988).

[5] J. E. Coffey, D. Hammer, D. M. Levin, and T. Grant, J. Res. Sci. Teach. 48, 1109 (2011).

[6] AAAS Science Assessment. $<$ http://assessment.aaas.org/items/EG022003\#/0>. Last retrieved June 21, 2016.

[7] M. C. Wittmann, C. Alvarado, and L. A. Millay, PERC 2015 created energy by working harder, instead? These explanations might lead to the same answer but for very different reasons. A teacher using tools such as clickers (or other multiple-choice tools for which no explanations are readily given by students) would need to ask additional questions to gather more information about students' ideas before proceeding.

\section{CONCLUSIONS}

In a professional development setting, teachers provided multiple possible explanations for a wrong answer to a question about gravitational potential energy. Importantly, these explanations spanned a broad space of (at times contradictory) explanations - their collective knowledge exposed all teachers in the room to more ideas than they might have named on their own. Their explanations made clear that teachers were aware of multiple ways of thinking about energy. Further, their explanations highlighted the ways in which similar, basic ideas (such as the substance metaphor for energy) could be used differently to answer the question. For teachers to listen well, they need an effective assessment that uncovers the details of student reasoning. This particular question did not do so. But, even with a more effective question, teachers would be left with the difficult task of understanding how to help students use their existing knowledge to develop new ideas and how to determine which ideas to support and which to confront.

\section{ACKNOWLEDGEMENTS}

We thank the teachers of the Maine Physical Sciences Partnership who participated in the activity. This work was supported in part by NSF grants MSP-0962805 and DRL1222580 .

$<$ http://www.compadre.org/Repository/document/Serv eFile.cfm?ID=13912\&DocID=4330>.

[8] R. Lancor, Sci. Educ. 23, 1245 (2012).

[9] R. Lancor, Int. J. Sci. Educ. 37, 876 (2015).

[10] E. Brewe, Phys. Rev. Spec. Top. - Phys. Educ. Res. 7, 020106 (2011).

[11] R. E. Scherr, H. G. Close, S. B. McKagan, and S. Vokos, Phys. Rev. Spec. Top. - Phys. Educ. Res. 8, 020114 (2012).

[12] J. Minstrell, in Res. Phys. Learn. Theor. Issues Empir. Stud. Proc. an Int. Work. Bremen, Ger. 1991, edited by R. Duit, F. Goldberg, and H. Niedderer (IPN, Kiel, 1992), pp. 110-128.

[13] J. Minstrell, in Cogn. Instr. 25 Years Prog., edited by D. Klahr and S. Carver (Lawrence Erlbaum Associates, Mawah, NJ, 2001), pp. 121-22.

[14] A. Gupta, D. Hammer, and E. F. Redish, J. Learn. Sci. 19, 285 (2010).

[15] D. Hammer, Am. J. Phys. 67, S45 (2000). 